\title{
Thermal hydraulic simulations of a PWR nuclear power plant
}

\author{
Said Mohamed Ali Ibrahim \\ Mechanical Engineering Department, \\ Faculty of Engineering, \\ AL-Azhar University, \\ Nasr City, Cairo, Egypt \\ Email: prof.dr.said@hotmail.com

\section{Sami Ibrahim Atia*} \\ Research and Development Department, \\ Nuclear Power Plants Authority, \\ Cairo, Egypt \\ Email: eng_sami2008@yahoo.com \\ *Corresponding author
}

\begin{abstract}
This research presents simulation analyses of steady state, station blackout, and loss of coolant accident thermal hydraulic conditions. The plant is a PWR type with output of about $1000 \mathrm{MWe}$. The simulations are performed by using RELAP and PCTran codes to develop a model of this PWR which could simulate its primary system, with good accuracy in cases of steady state, station blackout, and loss of coolant accidents. The modelled core temperature distribution, pressure, coolant mass flow inlet and outlet temperatures of the reactor, and other parameters proved to be in good agreement with reference data. These simulations verify the efficiency of management procedures in ensuring that the auxiliary cooling systems can cool the reactor core during accident conditions. The importance of the auxiliary system during the accident conditions is accredited. The developed RELAP and PCTran models are capable of reproducing the thermal hydraulic behaviour of the PWR.
\end{abstract}

Keywords: steady state; RELAP and PCTran codes; nuclear safety; station blackout; LOCA; thermal hydraulic.

Reference to this paper should be made as follows: Ibrahim, S.M.A. and Atia, S.I. (2019) 'Thermal hydraulic simulations of a PWR nuclear power plant', Int. J. Nuclear Safety and Security, Vol. 1, No. 1, pp.31-52.

Biographical notes: Said Mohamed Ali Ibrahim is Professor of Mechanical Power Engineering \& Energy, Al-Azhar University, Cairo. He has BSc \& MSc in Mechanical Engineering from Ain-Shams University, Cairo. He gained his $\mathrm{PhD}$ from Leeds University, England. He published tens of papers in scientific journals \& international conferences. He is an invited lecturer at universities and research centres in the world. He supervises postgraduates and has a good scientific school. He is the Chairman of the Academic Committee for Promotion of Academic Staff in the fields of Mechanical Power Engineering \& Energy, Al-Azhar University.

Sami Ibrahim Atia is Head of Mechanical Studies Division at Nuclear Power Plants Authority. He has BSc in Mechanical Engineering from Zagazig 
University, and MSc in Mechanical Engineering from Al-Azhar University. He has published many papers in International Journal of Nuclear Energy, Annals of Nuclear Energy and Progress of Nuclear Energy.

\section{Introduction}

The nuclear power plant safety depends greatly on the availability of a reliable and continuous source of cooling water during all modes and situations of the plant operation (Volkanovski and Prošek, 2011). Nuclear energy is an attractive available energy source which is capable of producing the large amounts of energy required to satisfy this ever increasing energy demand. So, safety of nuclear power plants is one of the most important general concerns (González-Mantecón et al., 2015).

In new designs of the nuclear reactors the adopted safety standards and features are incredibly strict and of paramount importance in order to reduce significantly the expected frequency of serious core accidents. Therefore, studies which provide knowledge and information in reactor safety are of important credibility. The present research furnishes knowledge in this arena.

The most challenging events of nuclear power plants (NPPs) are the station blackout condition that represents the loss of all sources of AC electrical power to all plant different equipment, which is vital to ensure that the cooling system is capable and efficient enough to remove continuously the decay heat generated by the nuclear fuel in the reactor core after reactor shutdown (Dinca et al., 2015), and the loss of coolant condition that represents the loss of the primary loop cooling reactor core cooling water, which is crucial for the continuous removal of the core decay heat after reactor shutdown (Borges and Sabundjian, 2015).

Station Blackout (SBO) leads to an immediate reactor trip with control rods being inserted by way of gravity upon loss of power. This action immediately shuts down the nuclear reactor (Dinca et al., 2015).

The loss of coolant accident (LOCA) is one of the most limiting design-basis accidents that causes the loss of coolant ability to remove heat from the nuclear fuel in the core. The most serious severe accident is the complete loss of the coolant (Licht et al., 2015).

This paper offers an analysis of the behaviour of a PWR NPP in case of a SBO initiating event occurring with reactor at full power and with the nuclear fuel at equilibrium condition, and the emergency core cooling system (ECCS) behaviour of a PWR nuclear reactor core for a loss of coolant accident in the primary circuit by employing PCTran code calculations. The rupture area is $200 \mathrm{~cm}^{2}$.

\section{Reference PWR NPP description}

The primary loop includes the heat source consisting of a nuclear core fuel in a reactor vessel. A pressuriser is connected to the hot leg to maintain a pressure above the saturation pressure to avoid bulk boiling of water (Westinghouse Electric Corporation, 2005). The secondary conventional loop is the heat utilisation cycle. 
Figure 1 A simplified schematic of the reference Westinghouse PWR plant design

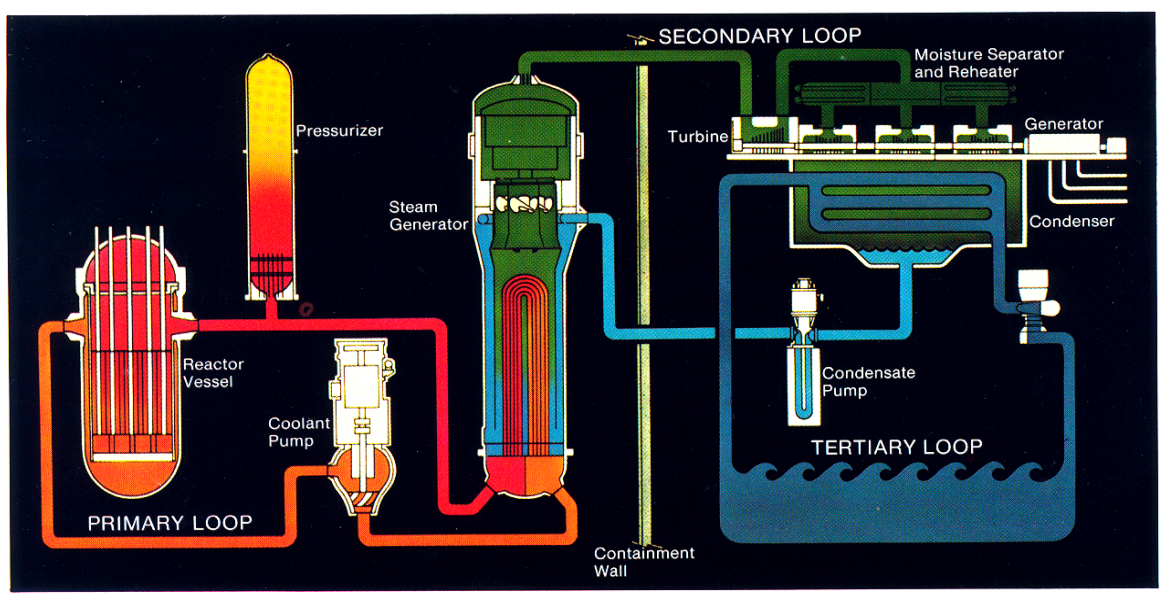

\section{RELAP and PCTran computer codes}

The RELAP thermal hydraulic code is designed to depict thermal hydraulic response of the overall reactor primary coolant system (RCS), core damage progression, release of the fission products and transport during severe conditions and accidents. It is able to performing simulations of steady-state, transient and accident conditions which include Loss of Coolant Accident (LOCA) and many types of transients condition in Light Coolant Water Reactors (LWRs) (The SCDAP/RELAP5 Development Team, 1997).

The RELAP thermal hydraulic code is based on two fluid models allowing for unbalanced temperatures and velocities of the fluids (The RELAP5-3D Code Development Team, 2009).

PCTran is offering comprehensive simulations of reactor power accidents. The cladding, coolant, and containment boundary radioactive leakage is traced by controls and animated monitors. This allows understanding the science and technology so as to protect the plant and public (Micro Simulation Technology, 2006). PCTran can simulate several of transient and accident conditions for nuclear plants. PCTran is a successful simulator for all types of nuclear reactors. It is designed for many different plant types, including BWR, PWR, AP1000, ABWR, and ESBWR (Micro Simulation Technology, 2006).

\section{Model description}

The nuclear power plant in this work is a pressurised coolant water reactor type. Figure 2 shows the nuclear power plant cycles description and nuclear fuel components and details. The plant is equipped with a pressurised water reactor with an electrical power output of about $1000 \mathrm{MWe}$, in which light water duplicates as coolant water and moderator of the reactor. The PWR is designed as a four loop plant but simulation merges each two loops in one loop. The main technical data of the plant are depicted in Table 1. 
Figure 2 The nuclear power plant cycles and nuclear fuel details

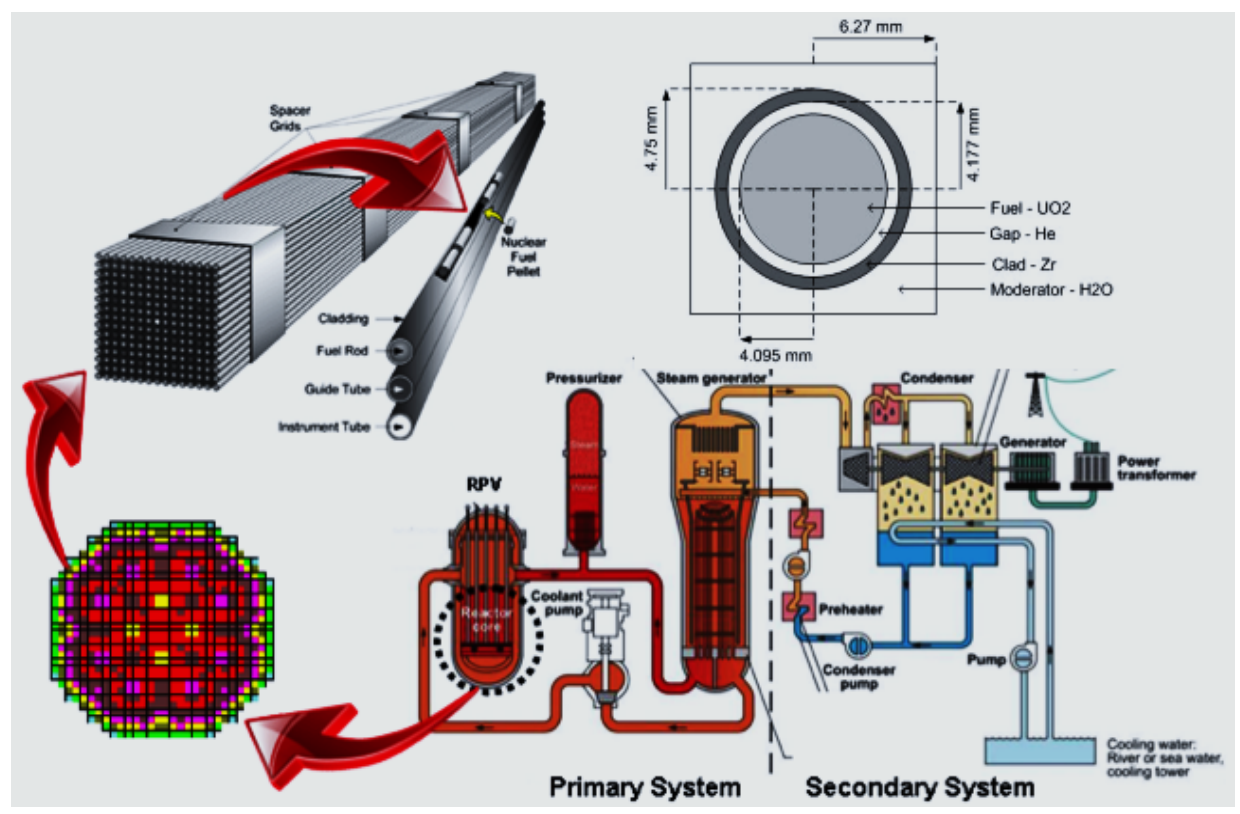

Table 1 Main technical data of the plant

\begin{tabular}{lcc}
\hline Parameter & Value & Unit \\
\hline Thermal power reactor output & 3322.3 & $\mathrm{MW}_{\mathrm{t}}$ \\
Electrical power output & 1000 & $\mathrm{MW}_{\mathrm{e}}$ \\
Reactor pressure & 155 & $\mathrm{bar}$ \\
Reactor temperature & 565.7 & $\mathrm{~K}$ \\
Total coolant mass flow rate & 18,630 & $\mathrm{~kg} / \mathrm{s}$ \\
Core mass flow rate & 17,700 & $\mathrm{~kg} / \mathrm{s}$ \\
Fuel active length & 3.66 & $\mathrm{~m}$ \\
Fuel rod diameter & 10.6 & $\mathrm{~mm}$ \\
Total number of fuel rods in the core & 50,952 & Fuel rods \\
Number of fuel assemblies & 193 & Fuel ass. \\
Number of fuel rods per assembly & 264 & Fuel rods \\
\hline
\end{tabular}

\section{RELAP model nodalisation}

The RELAP nodalisation diagram of the cycle adopted for the present simulation is obvious in Figure 3 for the reactor pressure vessel and the primary loop and it is based on the component design and operating data. 
Figure 3 The RELAP nodalisation diagram of the system

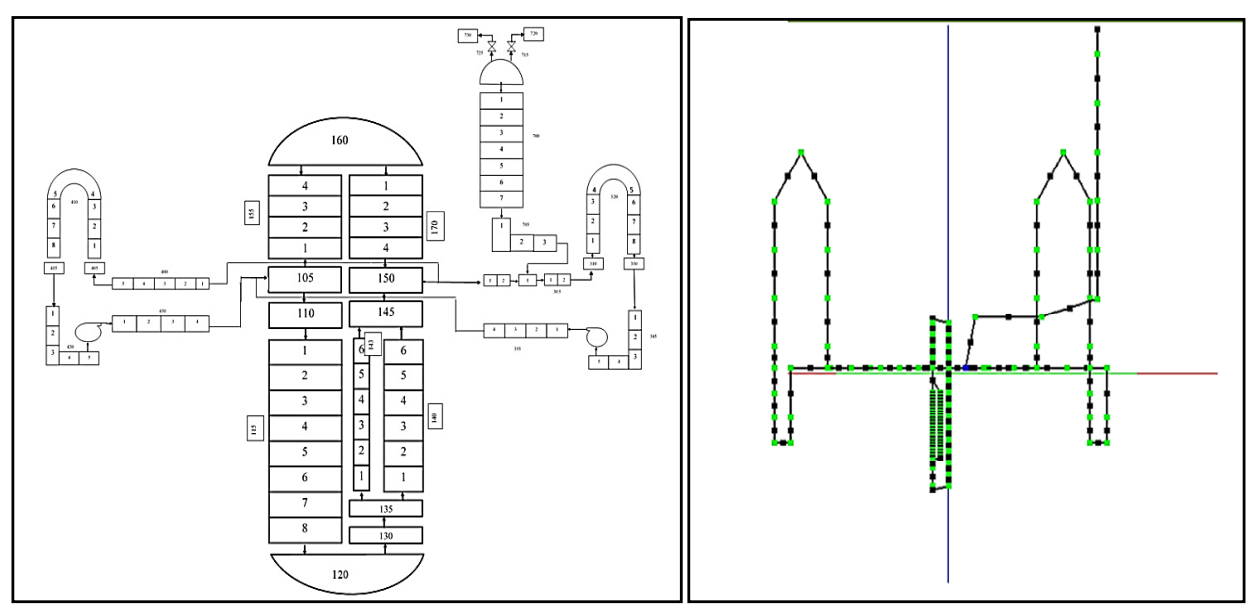

The nodalisation diagram of the PWR NPP model is shown in Figure 3. The results from the RELAP code, in the steady state, were validated with the main design technical parameters in Table 1. The nodalisation diagram is modelled for the components of a PWR NPP, which contains the reactor pressure vessel, two hot legs, two cold legs, two Reactor Coolant Pumps (RCPs), two Steam Generators (SGs), one Pressuriser (PZR) and surge line pipe, main feedwater and auxiliary feedwater systems.

The present model contains 87 hydrodynamic components and five heat structures (HSs). All the coolant loops are independently modelled. All loops have one steam generator (SG) that includes both the primary and secondary sides with heat exchange structures. The SG has both inlet and outlet plenums which are modelled as separate branches. Nodalisation of the secondary side is limited to the SG downcomer and riser, the SG dome and the main steam line. Also each loop has a reactor coolant pump (RCP) that is identical for each loop and contain actual characteristics. The coolant water flow rate for heat transfer through the core is about $17,700 \mathrm{~kg} / \mathrm{s}$. The model of the primary system has one pressuriser in the first loop as shown in the Figure 3, which also has two valves, one relief valve, and the other is a safety valve, and the connections between the components with hot leg, cold leg and intermediate leg.

\section{Layout of PCTran code PWR components}

The layout of PWR components on PCTran for the present simulation is indicated in Figure 4.

The results from the PCTran code, in transient condition, were validated with the key design parameters given in Table 1. The PCTran layout diagram is modelled for the components of PWR NPP during LOCA condition, which contains the reactor vessel, hot legs, cold legs, Reactor Coolant Pumps (RCPs), Steam Generators (SGs), Pressuriser (PZR), surge line pipe, Auxiliary Feedwater Lines, turbine island emergency feedwater systems EFWS, emergency core cooling systems ECCS, High pressure injection system (HPI), Low pressure injection system (LPI), and Accumulator (ACC). 
Figure 4 The layout of the PWR PCTran components (Micro Simulation Technology, 2006)

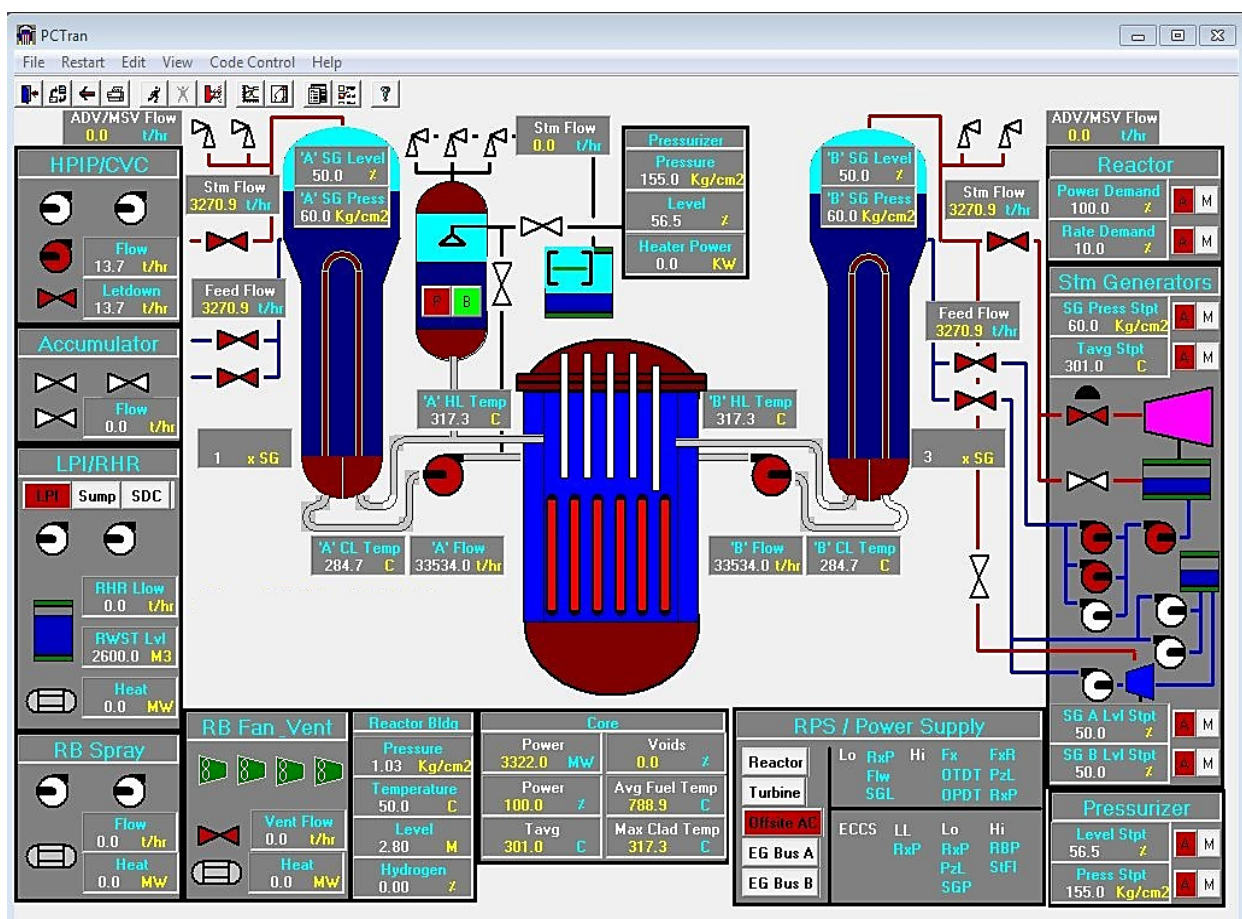

\section{Presentation of results and discussions}

\subsection{Steady state simulations}

RELAP code steady state simulations are performed for the PWR NPP operating at thermal power of about $3325.41 \mathrm{MW}_{\mathrm{t}}$. The steady state parameters were computed and compared with the nominal technical data which provided in the pressurised water reactor of Westinghouse manual. The results depict a well approval with the reference data and the computed errors are in correspondence with the familiar criteria for quantification of prediction quality of the steady state condition which was adopted (Bajs et al., 2003; Petruzzi and D'Auria, 2008). So, the present model simulation reproduces with good approximation the thermal hydraulic behaviour at the steady state condition of the reactor.

Transient time of $200 \mathrm{~s}$ is typically sufficient to achieve steady state conditions.

Figure 5 gives the coolant temperature at inlet and outlet of the reactor pressure vessel (RPV) time progression. As can be seen from the figure, the RPV reaches stable condition of the inlet and outlet temperatures in approximately $70 \mathrm{~s}$ of simulation during normal operation. This stability is caused by steady heat release from fission process. 
Figure 5 Time progression of coolant temperature at inlet and outlet of the RPV

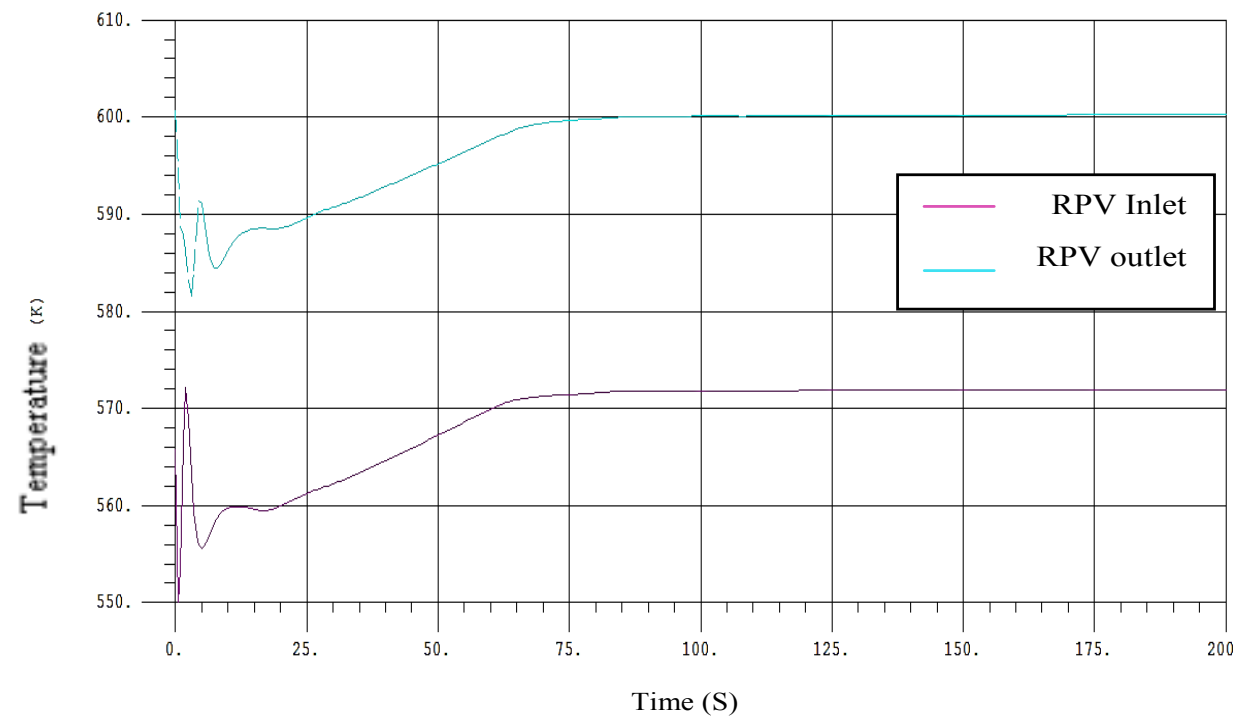

Figure 6 shows the coolant pressure at inlet and outlet of the reactor pressure vessel (RPV). The results depict that the pressure drop in the reactor pressure vessel is approximately 2 bar as expected by the code. This drop is caused by flow process in primary circuit and the friction in the pipes and components.

Figure 6 Time progression of coolant pressure at inlet and outlet of the RPV

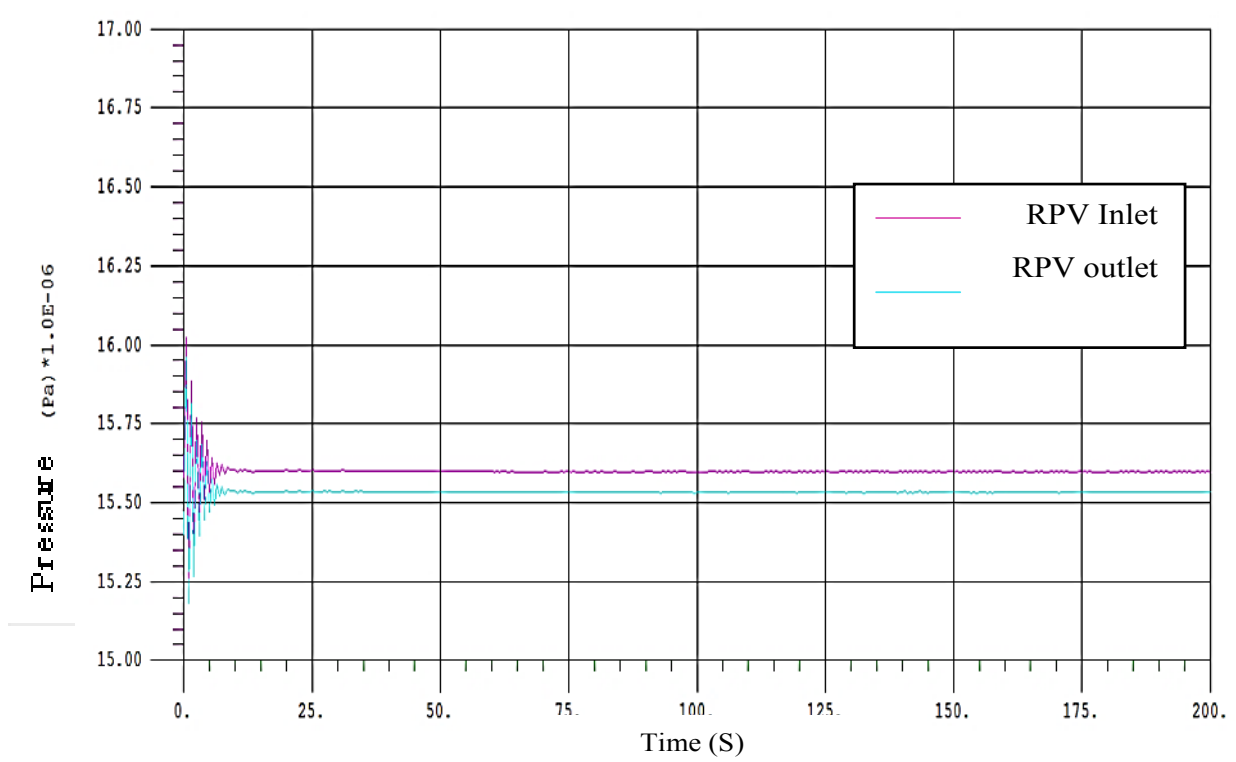


Figure 7 depicts the time progression for the heat structure 1140 (HS-140) nuclear fuel centreline temperature and Figure 8 shows the cladding surface temperature at five different axial levels. This stability is caused by the steady fission process and the heat release from this process.

Figure 7 Time progression of fuel temperature at different axial positions

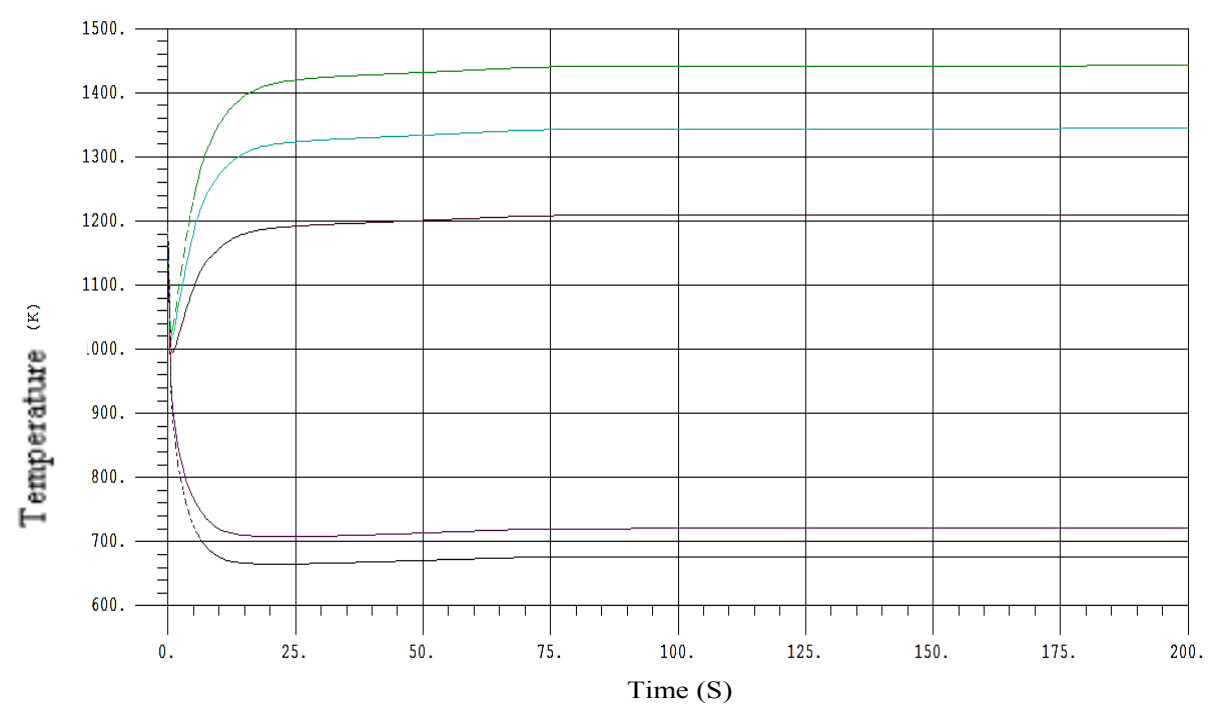

Figure 8 Time progression of cladding temperature at different axial positions

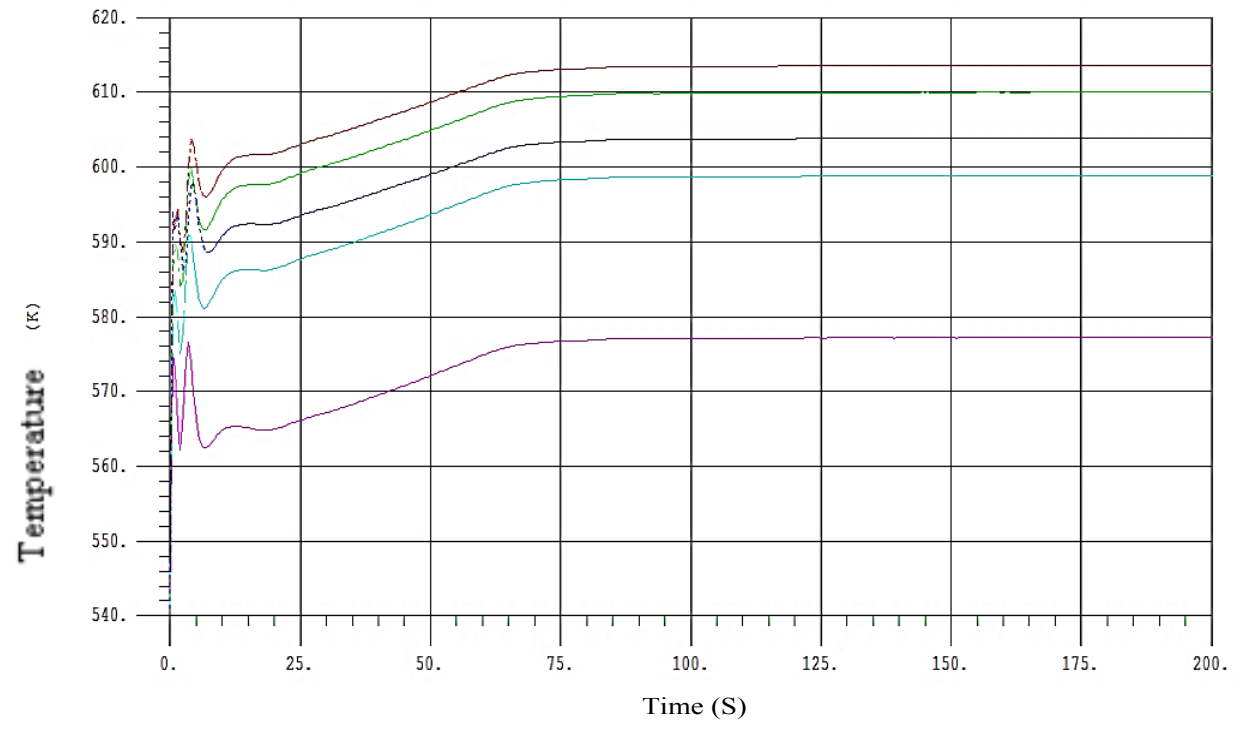


Figure 9 represents the progression of the fuel centreline and cladding temperatures at mid height for the heat structure 1140 associated with the hydrodynamic component 140 . It is clear these temperatures are completely stable and within the predicted range. This stability is caused by steady fission process and heat released.

Figure 9 Fuel and cladding temperature at half of elevation level

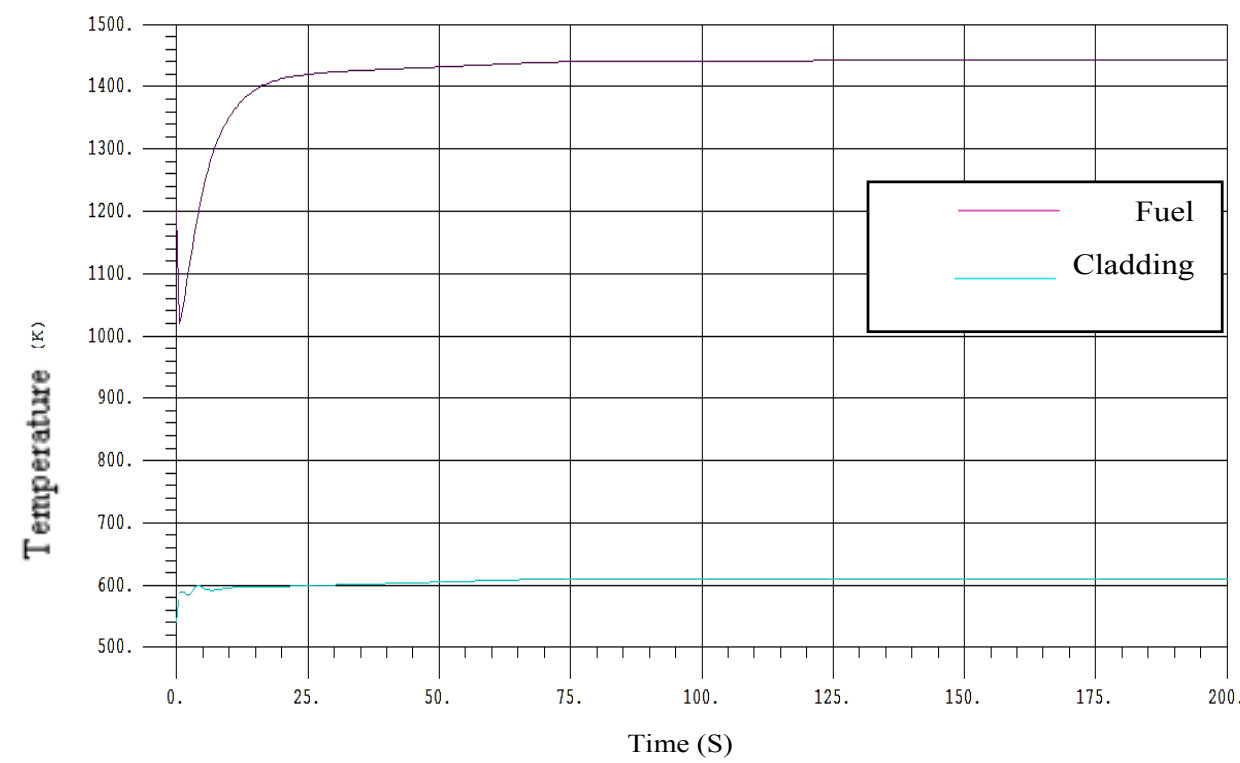

Figure 10 Axial distribution of fuel, cladding and coolant temperatures

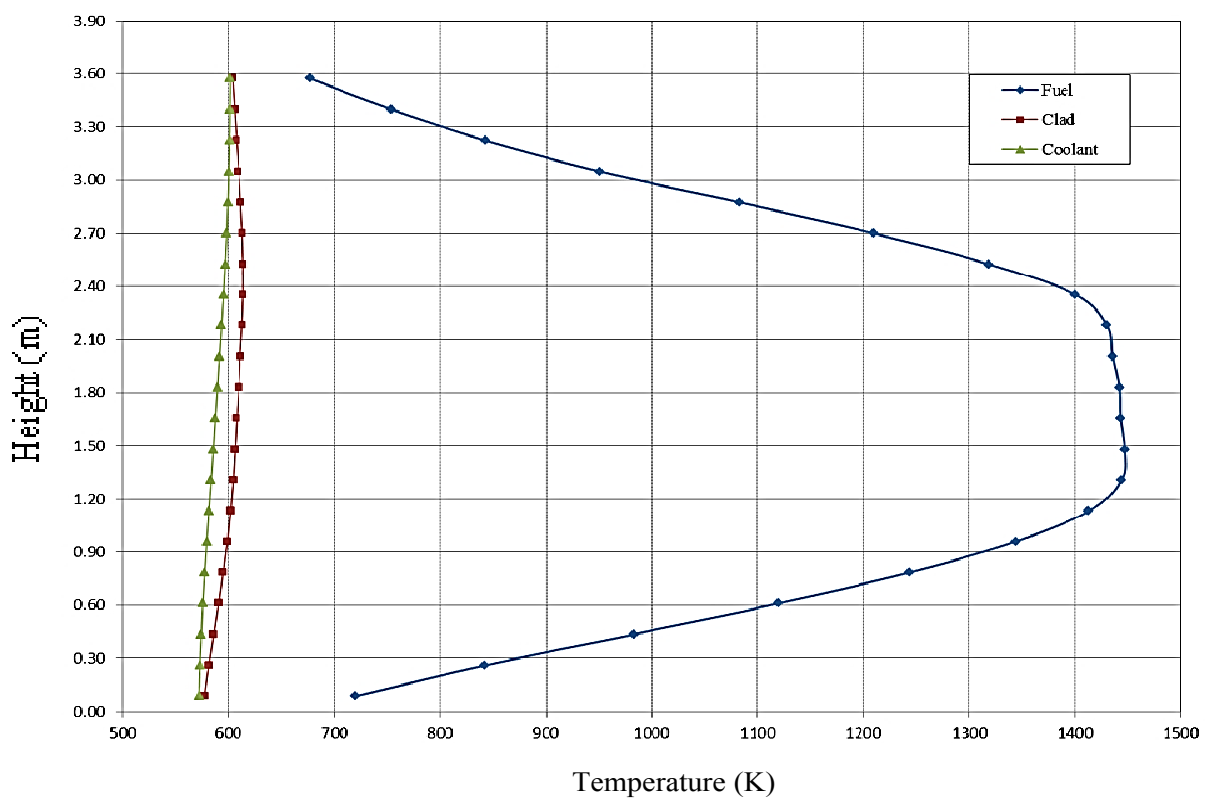


The axial distribution of fuel temperature follows the cosine-shaped profile, for the axial power distribution, and reaches the higher temperatures in the centre of the element as illustrated in Figures 10 and 11 for the HS-140. As expected, as the fluid moves along the heated length, the coolant water temperature increases. The results are agreeable with impractical predictions. This is caused by neutron density along the reactor core and fission process heat released.

Figure 11 Axial distribution of coolant and cladding temperatures

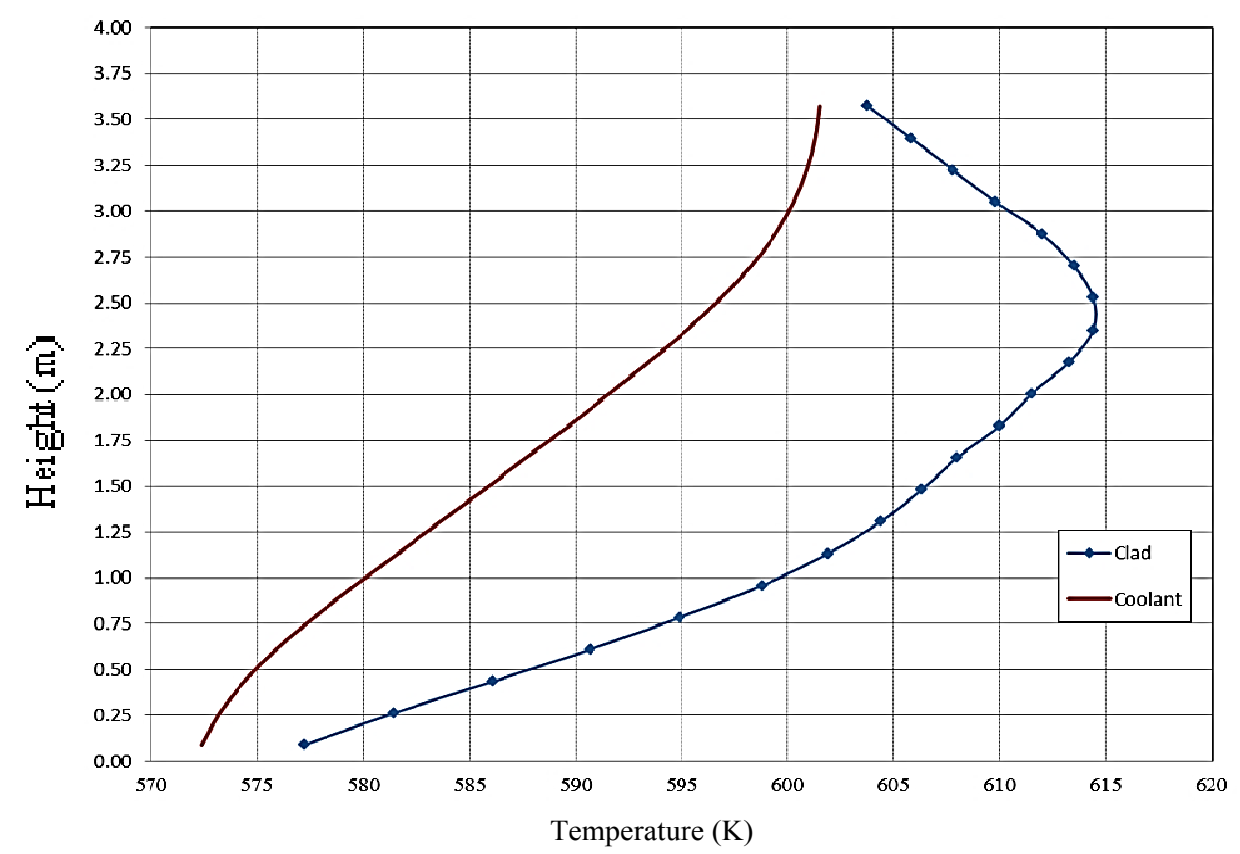

\subsection{SBO simulations}

The results acquired by the RELAP thermal hydraulic computer code are given in the following figures for a time of 8 hours which is the (DC) battery electrical power capacity which provides electrical power to the control systems.

Figure 12 indicates the reactor power level (total reactor power, reactor fission power, and total reactor power from decay of fission products and actinides), during station blackout condition and reactor trip result on control rod drops in the reactor and shutdown the reactor power and stop the fission process. The decay heat from the reactor core fission products still generated and decreases with cooling the reactor core.

Figure 13 depicts the RCP primary coolant flow system resulting from the sequences of station blackout condition where loss of All (AC) power for all components leads to RCP trip and stops the primary coolant flow. 
Figure 12 Total reactor power, reactor fission power, and total reactor power from decay of fission products and actinides during SBO

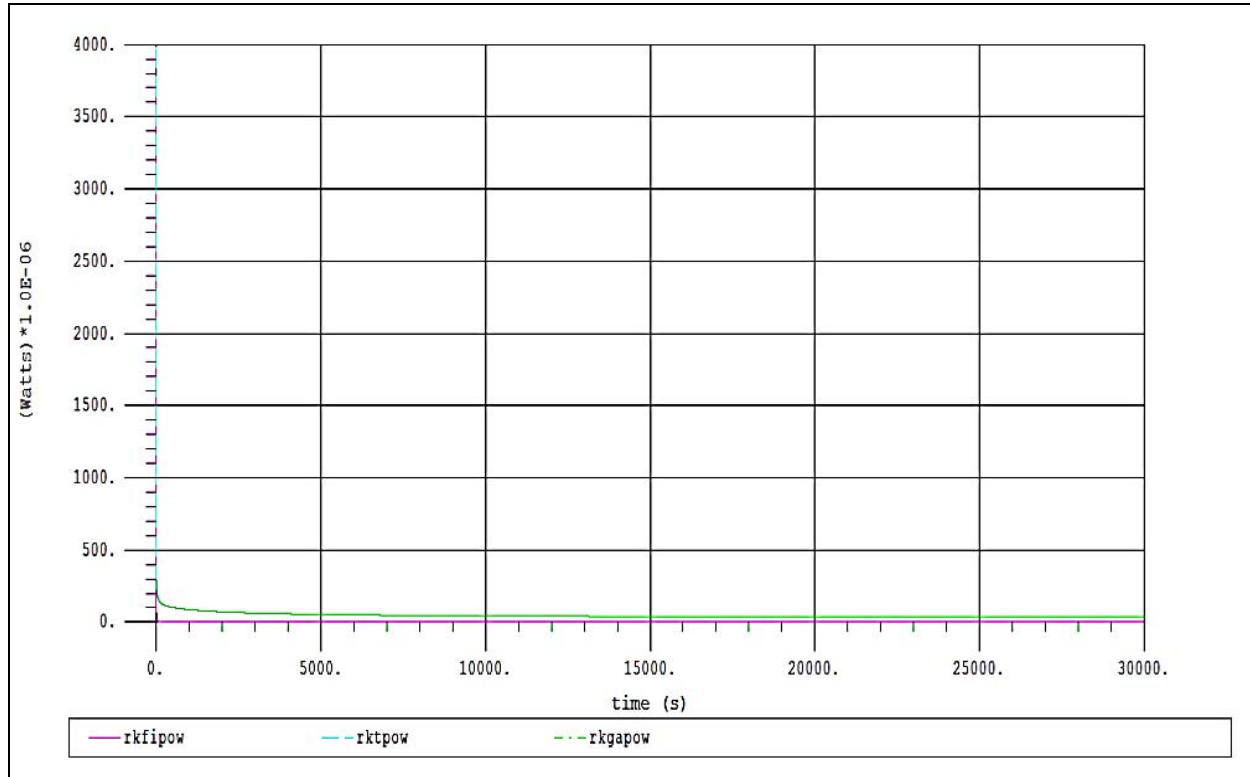

Figure 13 RCP primary coolant flow system

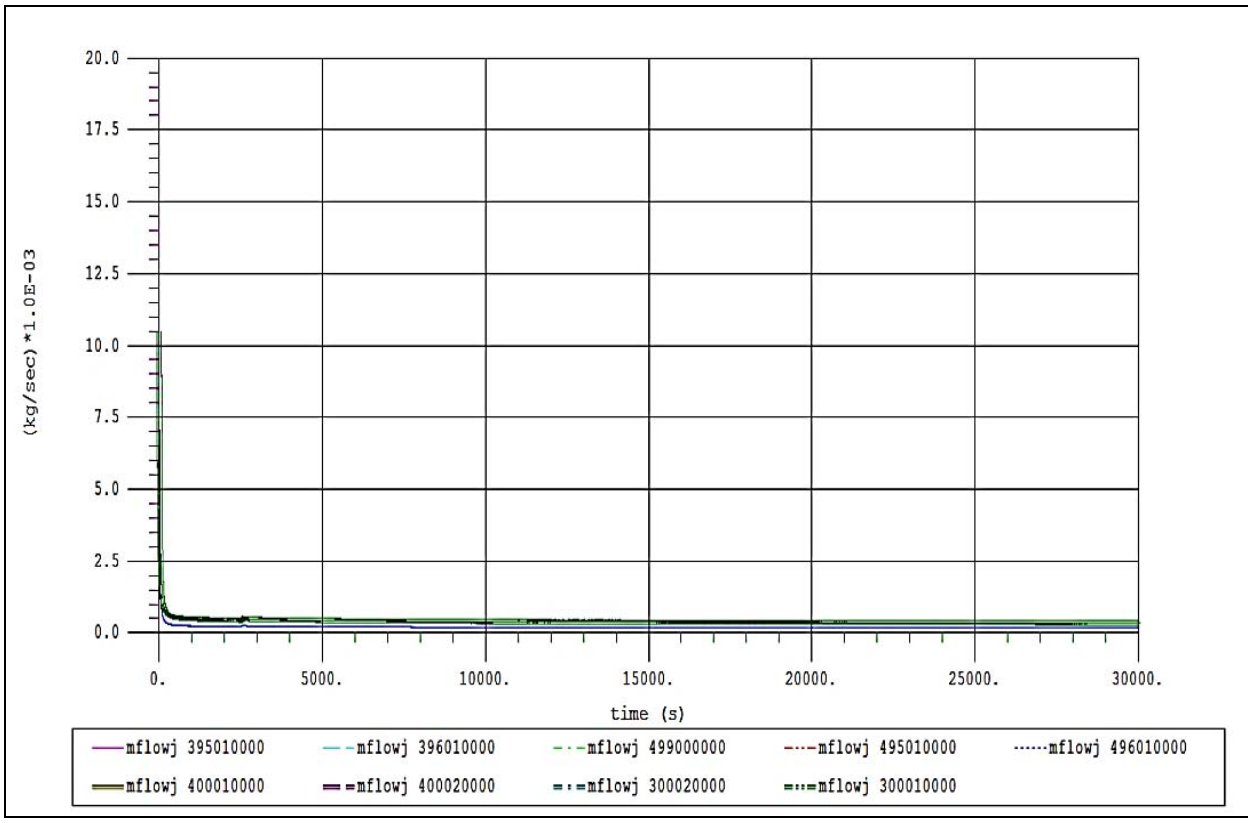

Figure 14 describes the pressure fluctuation and Figure 15 exhibits the leakage rate of the secondary circuit after SBO condition. The SG safety relief valves open if the pressure 
increases until attaining the valve set point which results in increase in feedwater temperature and the amount of leakage during opening the safety relief valves where the heat is transferred from the primary coolant to the secondary feedwater.

Figure 14 Pressure fluctuation of secondary circuit after SBO condition and the SG safety relief valves opening

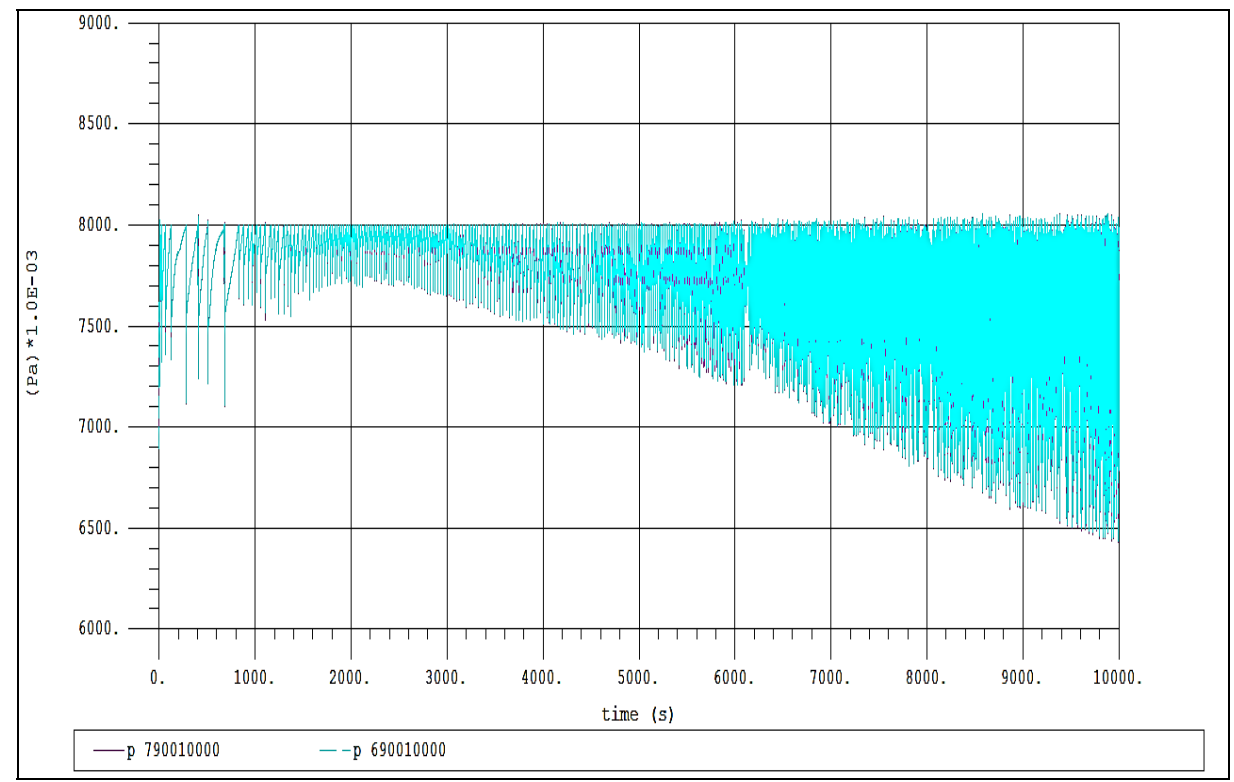

Figure 15 The SG safety relief valves a leakage rate during SBO event

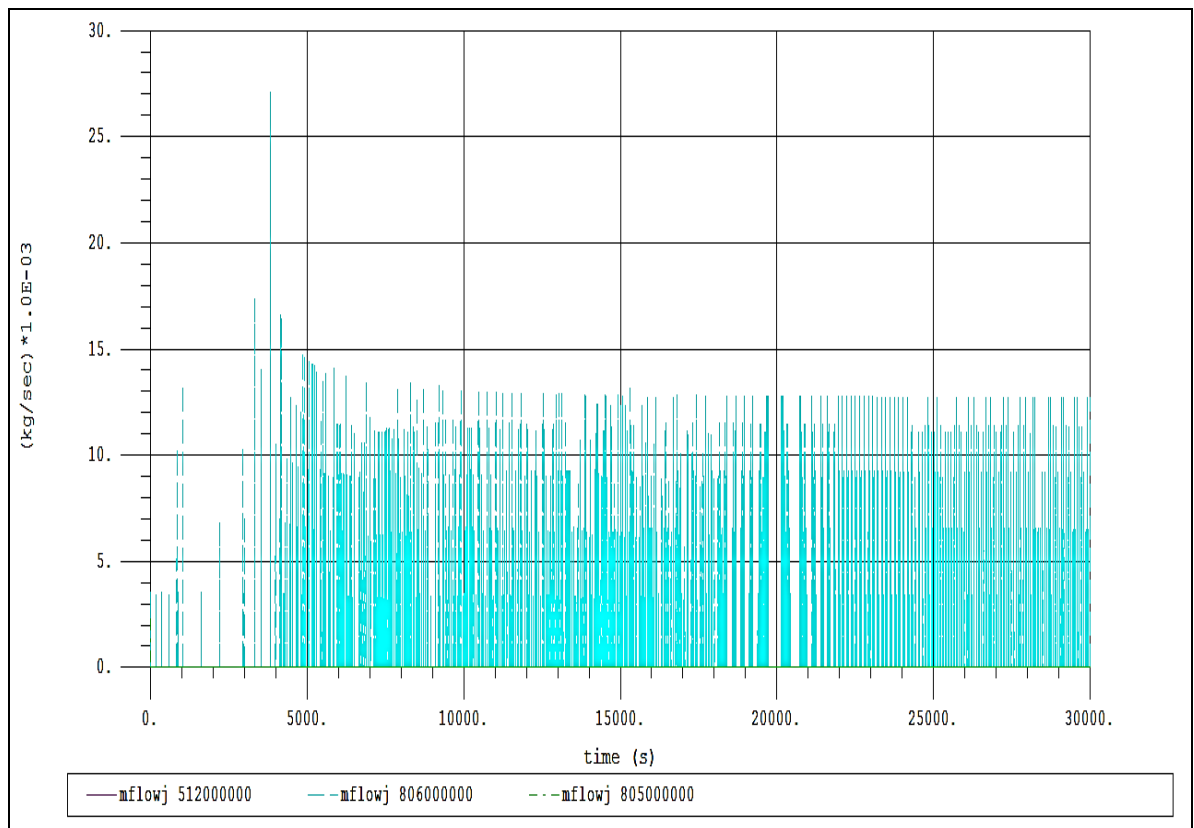


Figures 16 and 17 represent the axial distribution temperature progression of the fuel and cladding temperatures at different axial levels (from bottom to top of the height of fuel rod) for the heat structure. As observed, these temperatures are increased after SBO accident occurrence, and then become stable and decrease because of the sufficient safety measures taken and operation of TD AFWS in this case.

Figure 16 Time progression of the cladding temperature at different axial levels

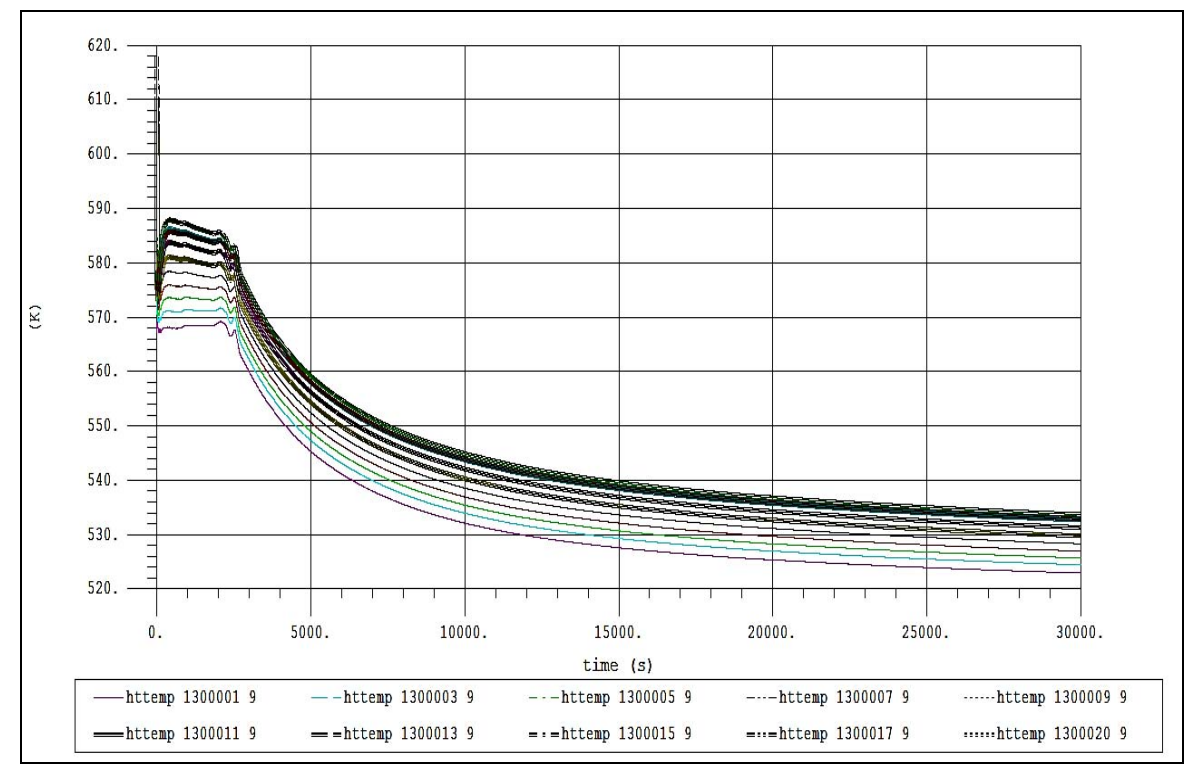

Figure 17 Time progression of the centreline temperature of core fuel at different axial levels

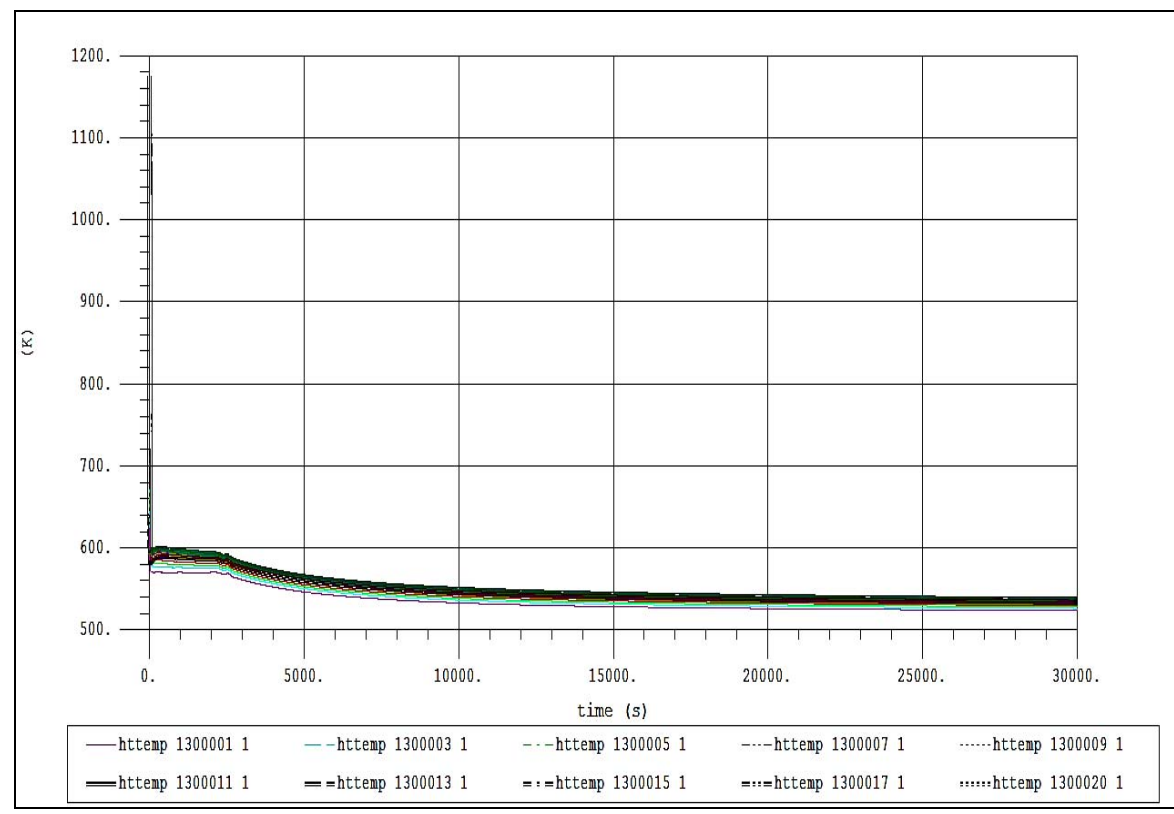




\subsection{LOCA simulations}

The simulation of this accident was performed by modelling the PWR and the emergency safety systems employed using the PCTran code which is designed to describe the emergency core cooling systems (ECCS) response and core behaviour under severe accident conditions. The sequence of events are summarised in Table 2.

Table 2 Time sequence of events of the accident progression

\begin{tabular}{lc}
\hline Event & Time (sec) \\
\hline Break initiation & 0 \\
Reactor scram from RCS pressure (pressure $\sim 13.22 \mathrm{MPa}$ ) & 5 \\
High pressure safety injection starts (HPSI) (pressure $\sim 12.97 \mathrm{MPa})$ & 10 \\
Accumulators injection start (ACC) (pressure $\sim 43$ bar) & 130 \\
Low pressure safety injection start (LPSI) (pressure $\sim 11.36$ bar) & 410 \\
Calculation terminated & 2000 \\
\hline
\end{tabular}

When the reactor coolant system (RCS) is at a pressure of about $13.22 \mathrm{MPa}$, the reactor protection system signal is generated to trip the reactor, at $5.5 \mathrm{~s}$. The control rods are inserted, to begin the fast shutdown of the reactor (i.e. stops the fission process and the reactor thermal power generation); the ECCS starts to supply water to the RCS. The initial break mass flow rate is much higher than the injection rate of the emergency safety injection systems pumps, then, the coolant inventory of the RCS is reduced continuously, and thus, the collapsed liquid levels in the reactor and the pressuriser decrease.

Consequently, the emergency core cooling systems (ECCSs) start to supply water when the RCS pressure decreases to $12.97 \mathrm{MPa}$, then the initial pressure of the high pressure safety injection (HPSI) system starts to inject cooling water into the reactor coolant system at $10 \mathrm{~s}$. Then, when the RCS pressure decreases to 43 bar, which is the initial pressure of the accumulators, the accumulators start to inject borated water into the reactor coolant system at $130 \mathrm{~s}$. After that, when the RCS pressure decreases to 11.36 bar, the initial pressure of the low pressure safety injection (LPSI) system, LPSI starts to inject cooling water into the reactor coolant system at $410 \mathrm{~s}$. The reactor and pressuriser level are recovered after about $600 \mathrm{~s}$ after the beginning of transient.

After about $2000 \mathrm{~s}$ transient condition started, and the volume of water injected by the ECCS is sufficient to compensate for the loss of coolant water through the break leakage. The ECCS injection was enough to keep the fuel and cladding temperatures within the safe limits. At the start of the transient, the cladding temperature starts to increase, reaching a peak of $789.3^{\circ} \mathrm{C}$ at $10 \mathrm{~s}$, with the fast prompting of protection and control system. This temperature increase does not reach rates beyond the allowed temperature limits and thus, the reactor core integrity is ensured.

All the transient time sequences of event given above are clearly indicated and verified in the present results shown in the coming figures.

Figure 18 indicates the break flow, during LOCA conditions and flow through the break reaches a maximum value of approximately $3300 \mathrm{~kg} / \mathrm{s}$ after $5 \mathrm{~s}$ where in the beginning the reactor coolant pressure is high, later on, it has a decreasing trend as the steam depressurises as shown in Figure 18. 
Figure 18 Break flow during HL LOCA accident conditions

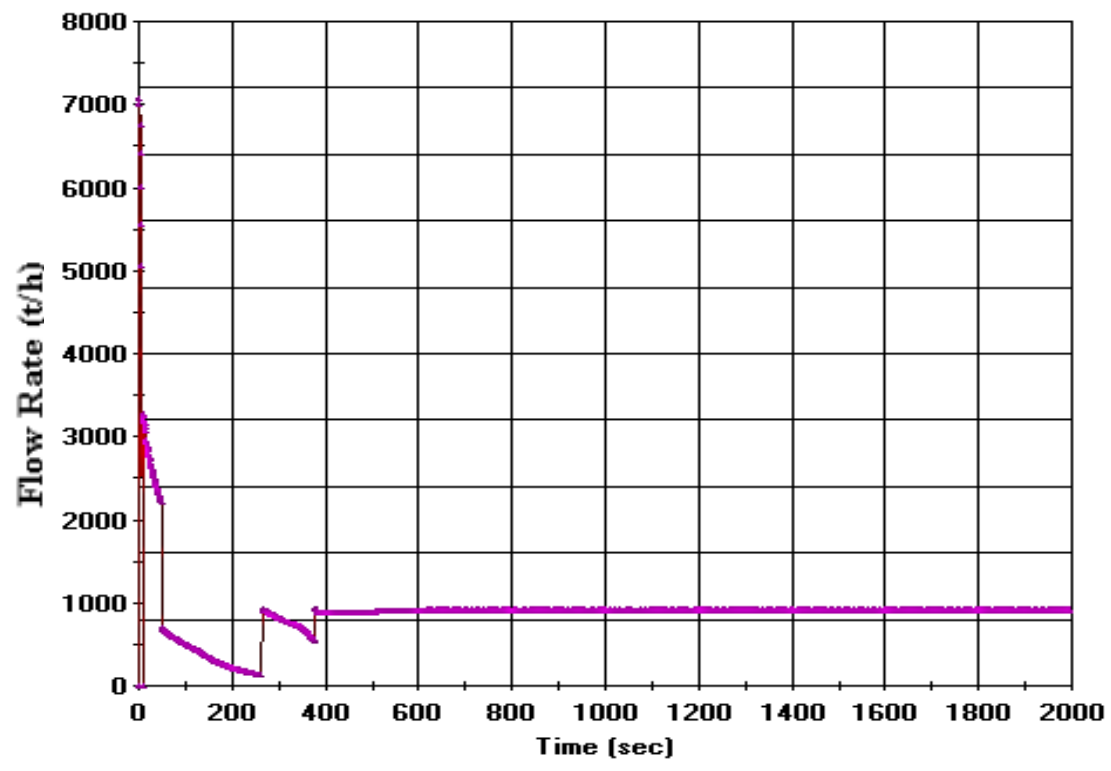

Figure 19 gives the reactor power level (the reactor total megawatt thermal power, thermal core power level, and power neutron flux level) during LOCA conditions. Shutdown of the reactor is performed by inserting the control rods in the reactor and stops the fission process and the reactor thermal power generation. The decay heat from the reactor core fission products continues to generate and then decreases with cooling the reactor core.

Figure 19 The reactor total megawatt thermal power, thermal core power level, and power neutron flux level during HL LOCA accident conditions
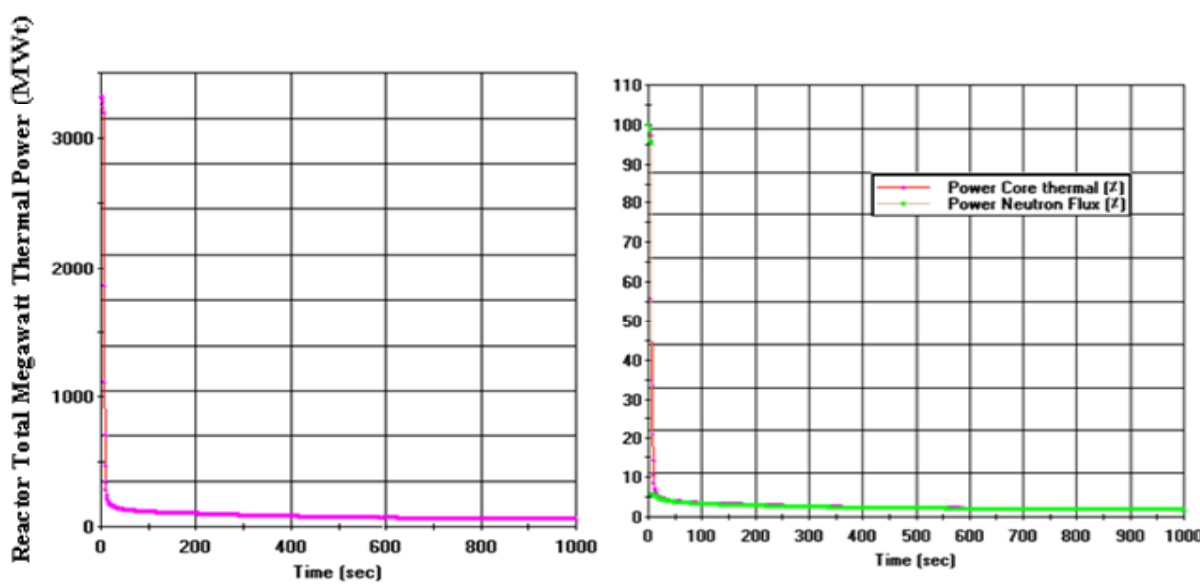

Figure 20 illustrates the reactor primary loop pressuriser level during hot leg (HL) LOCA accident conditions. The pressuriser level decreases sharply from its steady state value at 
$56.5 \%$ to zero at $30 \mathrm{~s}$, and the pressure reaches $120 \mathrm{bar}$, then the volume of the system cooling water decreases which results from the break leakage in the leg. The emergency core cooling systems operate and supply cooling water to the RCS, then refill the pressuriser and increase the pressuriser level after $600 \mathrm{~s}$.

Figure 20 Primary loop pressuriser level during HL LOCA conditions

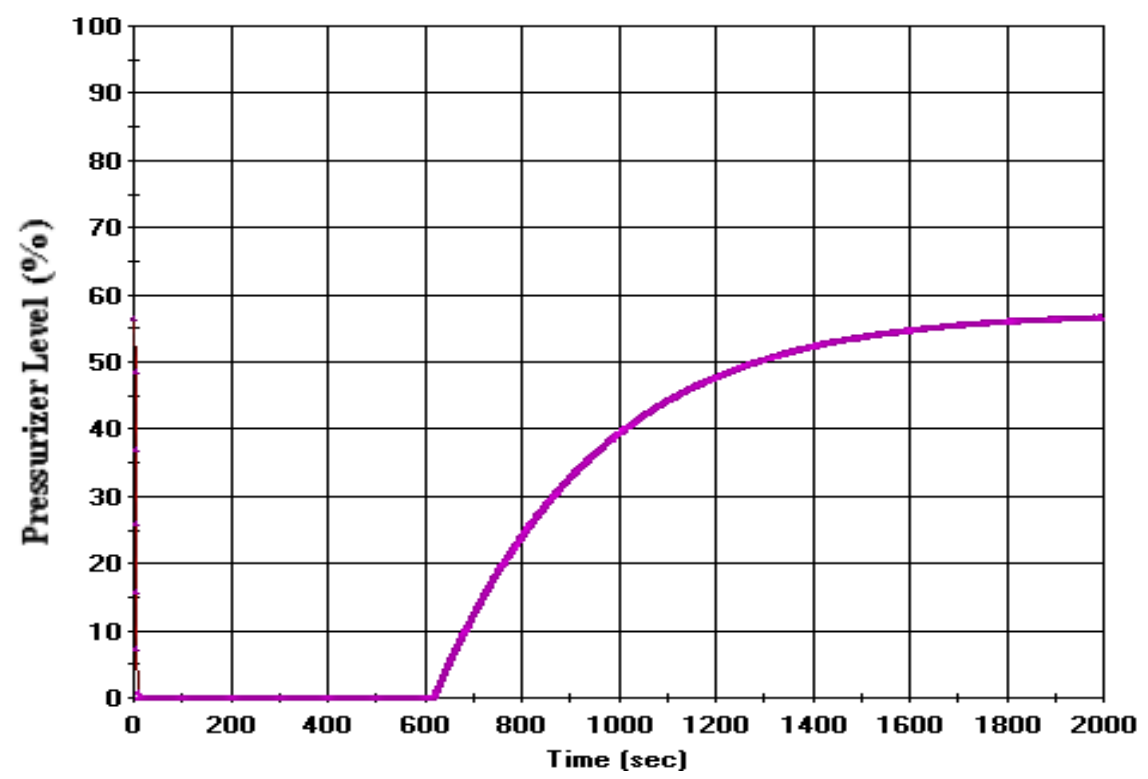

Figure 21 High pressure injection system (HPI) response and flow rate during HL LOCA conditions

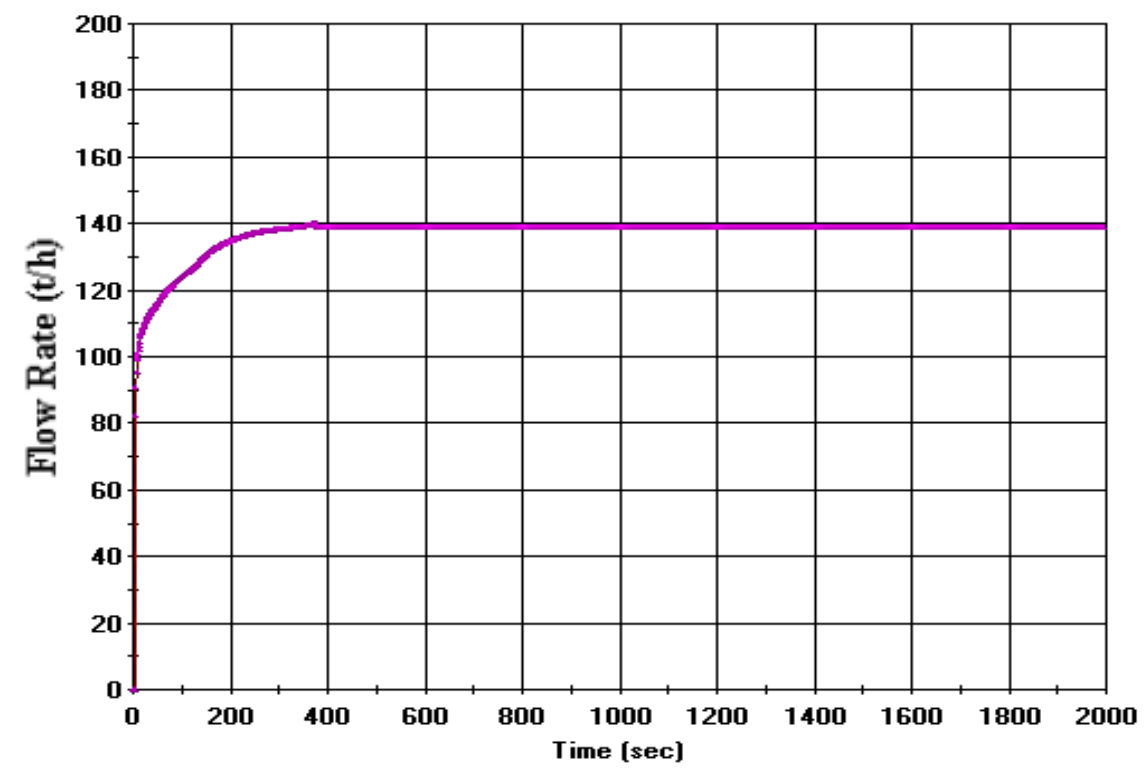


Figure 21 depicts the high pressure injection system (HPI) response and flow rate during HL LOCA conditions. The high pressure injection system started to inject water into the reactor vessel to continuously remove the core decay heat. After the scram which occurs at $5.5 \mathrm{~s}$, the safety injection system (SIS) receives the signal and is initiated at $10.0 \mathrm{~s}$. As the high pressure safety injection starts at a pressuriser pressure of $12.9 \mathrm{Mpa}$ accompanied with increase in the flow rate to reach a maximum value at $500 \mathrm{~s}$ as shown in Figure 21.

Figure 22 presents the accumulator response and flow rate during HL LOCA conditions. The accumulator started at $130 \mathrm{~s}$, when the pressure reaches approximately 43 bar and injected water into the reactor vessel to remove the core decay heat.

Figure 22 Accumulator response and flow rate during HL LOCA conditions

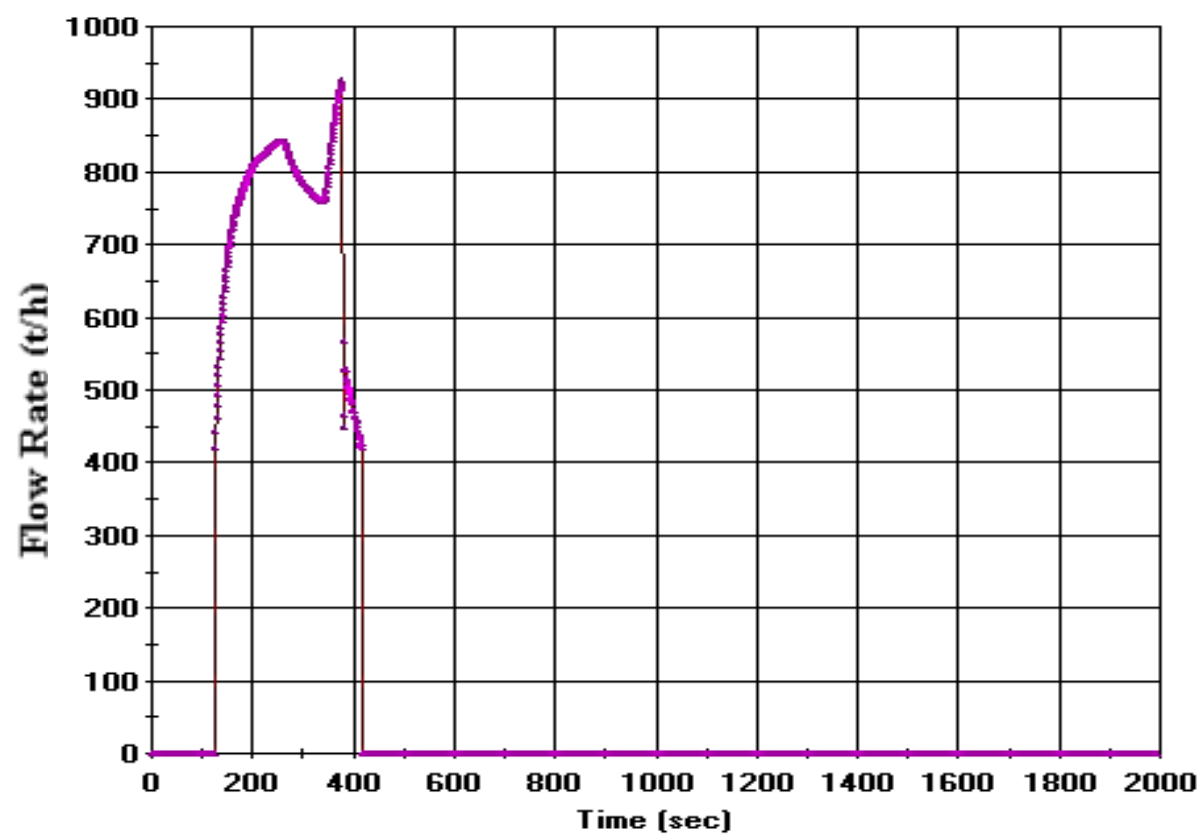

Figure 23 shows the low pressure injection system (LPI) response and flow rate during HL LOCA conditions. The low pressure injection system started after the accumulator flow rate finished at $410 \mathrm{~s}$ and injected water into the reactor vessel for the continuous removal of the core decay heat at low pressure.

Figure 24 indicates the total flow of ECCS during HL LOCA conditions. The ECCS contains three main systems: HPI, Accumulator, and LPI systems. The ECCS injection was sufficient to keep the fuel and cladding temperatures within the safe limits. The combined flow of these three systems is shown in Figure 24. 
Figure 23 Low pressure injection system (LPI) response and flow rate during HL LOCA conditions

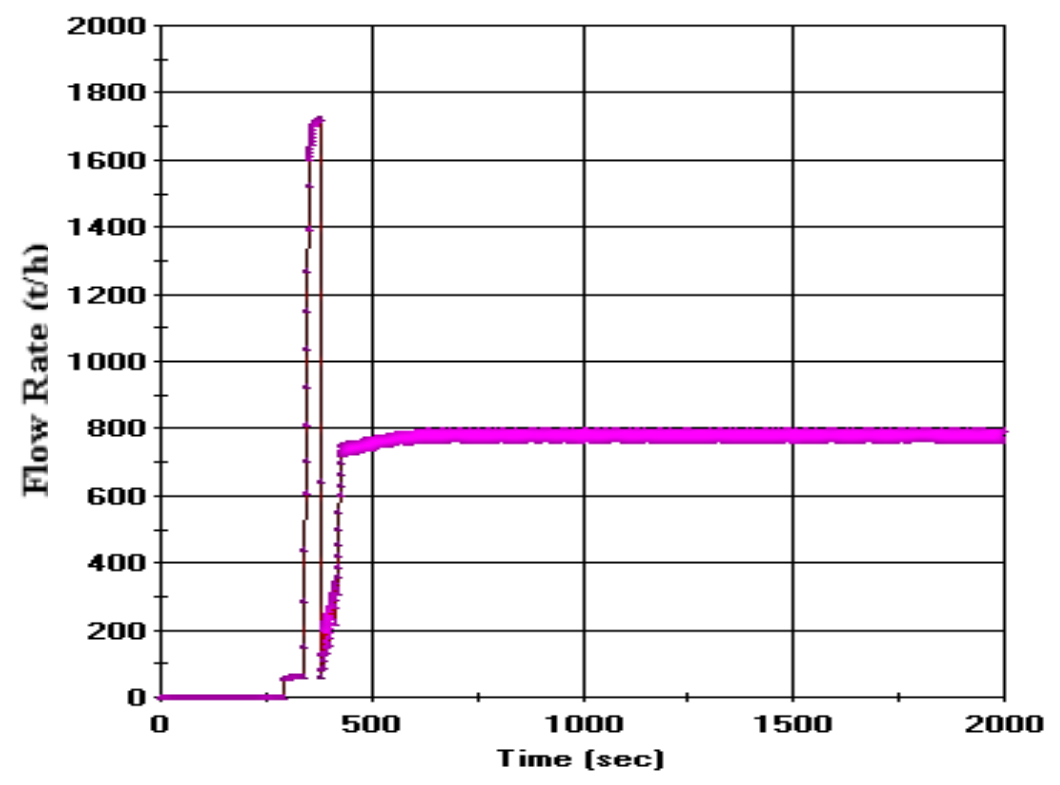

Figure 24 Total flow of ECCS during HL LOCA conditions

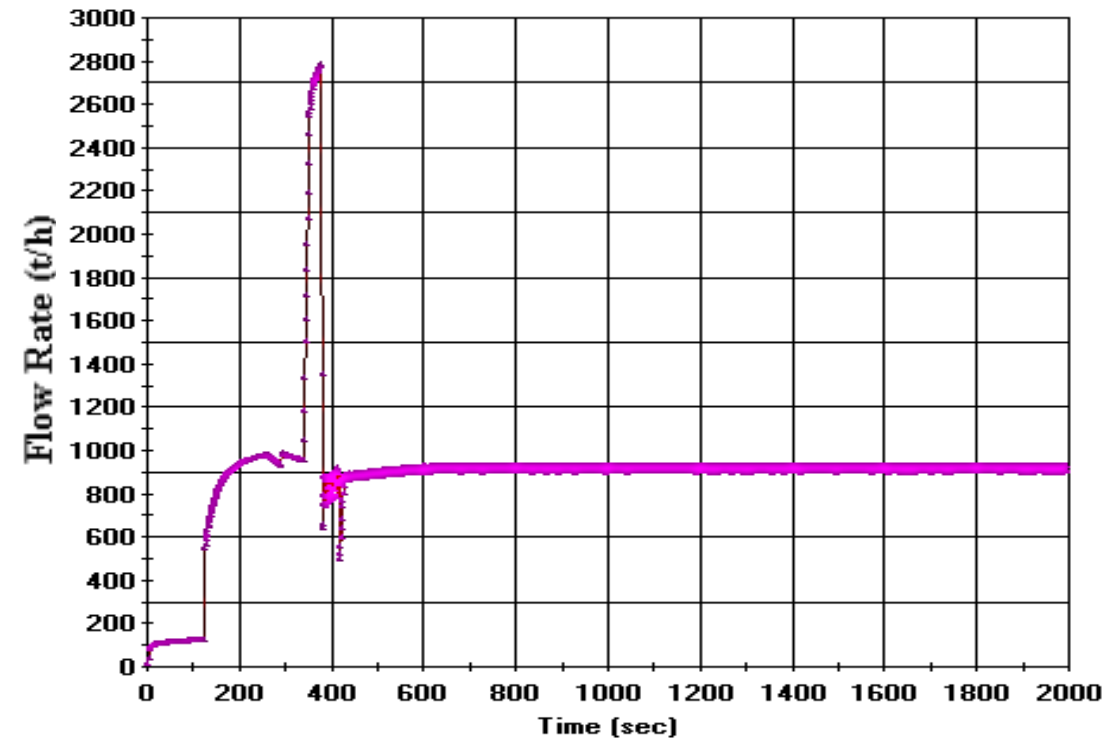

Figure 25 illustrates the average peak clad temperature and the average peak fuel temperature during HL LOCA conditions. As observed, these temperatures decreased after the LOCA accident occurrence because of the sufficient safety measures taken and the operation of the ECCS in this case. 
Figure 25 The average peak clad and the average peak fuel temperatures during HL LOCA conditions

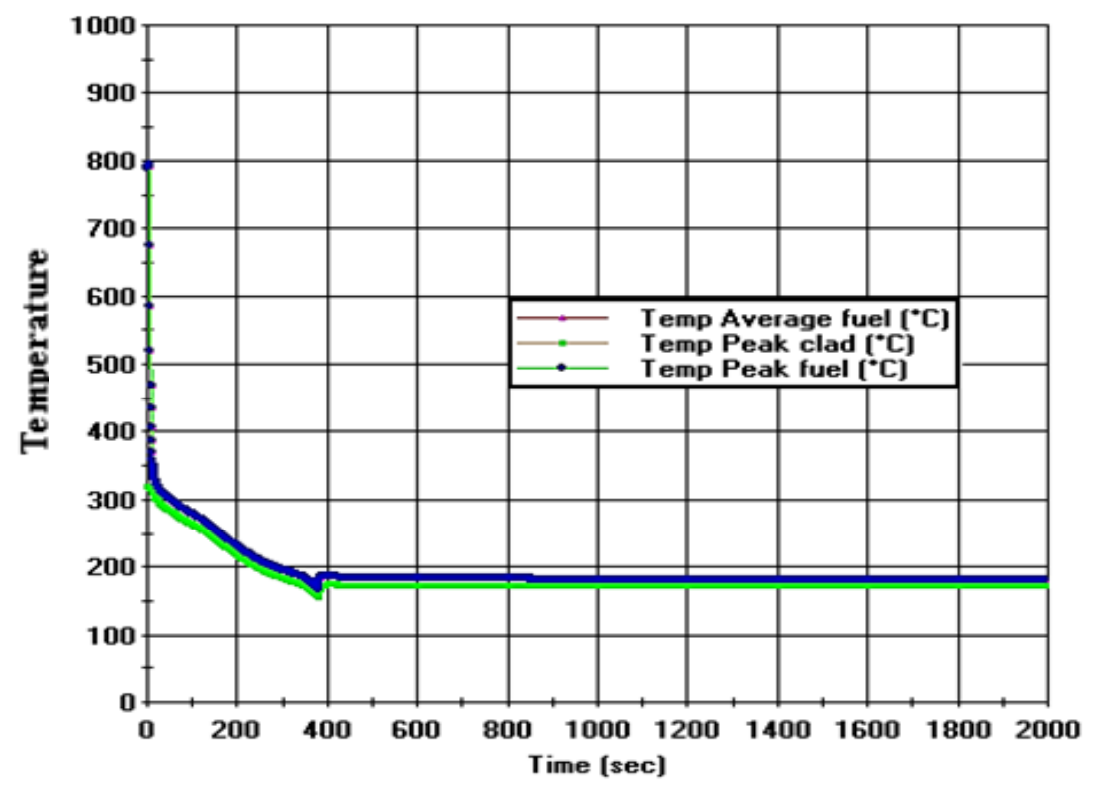

Figure 26 depicts the relation between the amount of hydrogen $\left(\mathrm{H}_{2}\right)$ generated by zirconium-coolant $\left(\mathrm{Zr}-\mathrm{H}_{2} \mathrm{O}\right)$ interaction and time during HL LOCA conditions. The graph shows that there is no generation of $\mathrm{H}_{2}$ because no interaction occurs between the clad and the coolant water where the clad surface temperature is within the safe limits.

Figure 26 The mass of $\mathrm{H}_{2}$ generated by $\mathrm{Zr}-\mathrm{H}_{2} \mathrm{O}$ during $\mathrm{HL}$ LOCA conditions

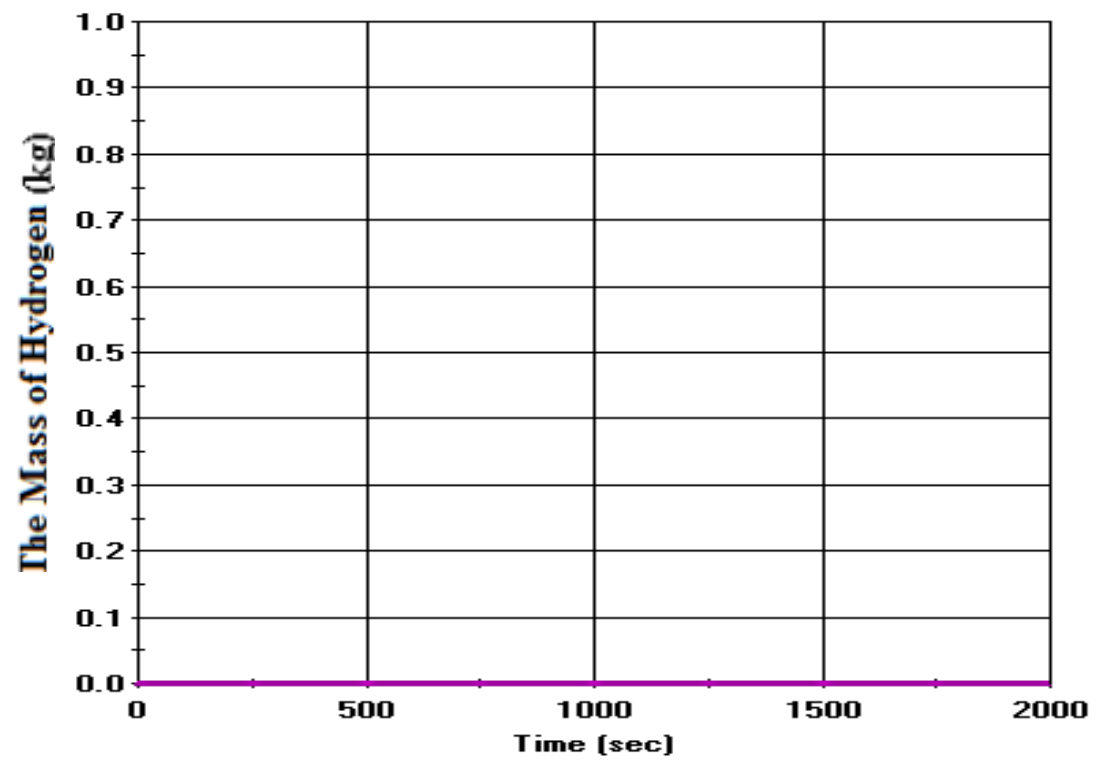




\section{Conclusions}

A thermal hydraulic model for the pressurised water reactor primary system was developed by using engineering and technical data from the reference pressurised water reactor nuclear power plant of the Westinghouse manual. The results from the present model were compared with the reference technical data and found in good agreement. Thus, simulations of the reactor behaviour during steady state, SBO, and LOCA conditions can describe the reactor behaviour in real life. For the simulated case, the analysed and examined parameters demonstrated that the model could successfully depict the reactor performance in steady state operating conditions. The results are abundantly important as far as safety of nuclear reactors is concerned.

Mitigation procedures against station blackout consequences were examined. From the results, the analysis of the station blackout accident demonstrates that the TD-AFWS can provide sufficient cooling to prevent threat and damage to the reactor core. Therefore, TD-AFWS of PWR are necessary and vital to mitigate the consequences of station blackout event.TD-AFWS provide approximately 8 hours or more of additional time for the operator to recover and restore the electrical power source to prevent the damage of reactor core. So, we recommend that the extension of the power capacity of batteries can be an active way to continue AFWS operation to mitigate the extended time of station blackout event (SBO).

Thus, simulations of the reactor behaviour during station blackout can describe the reactor behaviour in actual operating conditions. For the simulated case, the analysed and examined parameters demonstrated that the model could successfully depict the reactor performance in station blackout conditions. The results are extremely important for the safety of nuclear reactors.

Additional procedures should be taken to mitigate the effect of station blackout accident. For instance the Korean Reactor Design APR-1400 used safety injection tank (SIT) to cool down the reactor core until restoration of the electrical power source, use coolant water spent fuel pool, or redundancy and diversity types of electrical power sources(i.e. portable power sources, sealed diesel generators rooms)

Mitigation procedures have been evaluated against LOCA consequences. Therefore, the LOCA of the PWR is investigated to assess the efficiency and the effectiveness of the mitigation procedures. The severe accident loss of coolant accident (LOCA) study focuses on the performance of emergency safety systems response of the PWR. The simulation analysis of the $200 \mathrm{~cm}^{2}$ break depicts the reactor behaviour during hot leg loss of coolant accident conditions.

The analysis of the hot leg break demonstrates that the ECCS can provide sufficient cooling to prevent threat to the core. In the long term, the ECCS keeps the reactor coolant system filled and the decay heat is removed partly by the break flow.

Furthermore, the core must keep amenable to cooling during and after the event. The criteria were established to provide significant margin in the emergency core cooling system performance following LOCA condition. The results depict the good actuation of the ECCS, guaranteeing the integrity of the nuclear power reactor core. In addition, the results obtained using PCTran were compared with the technical data of the FSAR of the reference nuclear power reactor and found in good agreement. 
Recommendations are necessary to ensure and enhance protection against severe accidents and to strengthen emergency procedures preparedness and mitigation actions.

\section{References}

Bajs, T., Grgić, D., Sêgon, V., Oriani, L. and Conway, L.E. (2003) 'Development of a RELAP5 Nodalization for IRIS Non-LOCA Transient Analyses', Nuclear Mathematical and Computational Sciences: A Century in Review, Springer, Gatlinburg, USA.

Borges, E.M. and Sabundjian, G. (2015) 'Flow regimes and heat transfer modes identification in Angra 2 core, during small break in the primary loop with area of $100 \mathrm{~cm}^{2}$, simulated with RELAP5 code', International Nuclear Atlantic Conference - INAC 2015, 4-9 October, São Paulo, SP, Brazil.

Dinca, E., Dupleac, D. and Prisecaru, I. (2015) 'Verification by analytical means of the efficiency of some accident management measures for SBO at a CANDU-6 NPP', International Nuclear Safety Journal, Vol. 4, No. 4, pp.9-22.

González-Mantecón, J. et al. (2015) 'Thermal hydraulic simulations of the Angra 2 PWR', Proceedings of ICAPP 2015, 3-6 May, Nice, France.

Licht, J.R., Dionne, B., Van den Branden, G., Sikik, E. and Koonen, E. (2015) RELAP5 Model Description and Validation for the BR2 Loss-of-Flow Experiments, U.S. Department of Energy, National Nuclear Safety Administration NNSA, ANL/GTRI/TM-14/10.

Micro Simulation Technology (2006) PCTran for PWR and AP1000, Ver. 5.0.4, USA, 2000, and User Manual 2006.

Petruzzi, A. and D'Auria, F. (2008) 'Thermal hydraulic system codes in nuclear reactor safety and qualification procedures', Science and Technology of Nuclear Installations, http://dx.doi.org/ $10.1155 / 2008 / 460795$.

The RELAP5-3D Code Development Team (2009) RELAP5-3D User's Manual, Idaho National Laboratory, Idaho Falls.

The SCDAP/RELAP5 Development Team (1997) SCDAP/RELAP5/MOD3.2 Code Manual, Vols. I-IV, NUREG/CR-6150, INEL-96/0422, October.

Volkanovski, A. and Prošek, A. (2011) 'Station blackout and nuclear safety', Proceedings of the International Conference Nuclear Energy for New Europe, Bovec, Slovenia, 12-15 September.

Westinghouse Electric Corporation (2005) Westinghouse pressurized water reactor nuclear power plant, Water Reactor Divisions. 


\section{Nomenclature}

$\begin{array}{ll}\text { AC } & \text { Alternating Current } \\ \text { DC } & \text { Direct Current } \\ \text { DDP } & \text { diesel driven pumps } \\ \text { EDG } & \text { Emergency Diesel Generators } \\ \text { HS } & \text { Heat structures } \\ \text { LOCA } & \text { Loss of Coolant Accidents } \\ \text { LWRs } & \text { Light Water Reactors } \\ \text { NPP } & \text { Nuclear power plant } \\ \text { NRC } & \text { Nuclear Regulatory Commission } \\ \text { PWR } & \text { Pressurised water reactor } \\ \text { RC } & \text { Reactor coolant } \\ \text { RCPs } & \text { Reactor coolant pumps } \\ \text { RCS } & \text { Reactor coolant system } \\ \text { RPV } & \text { Reactor pressure vessel } \\ \text { SG } & \text { Steam generator } \\ \text { SBO } & \text { Station Blackout } \\ \text { TD-AFWS } & \text { Turbine Driven Auxiliary Feedwater System } \\ \text { TDP } & \text { turbine driven pumps } \\ \text { UO2 } & \text { uranium oxide } \\ \text { ZrO2 } & \text { zirconium oxide }\end{array}$

